\title{
CARDIOVASCULAR RESPONSES OF BEGINNER AND ADVANCED PRACTITIONERS TO DIFFERENT VOLUME AND INTENSITY RESISTANCE EXERCISE PROTOCOLS
}

\author{
Leandro Paes Ferreira ${ }^{1}$; Osvaldo Costa Moreira ${ }^{2}$; \\ Lucas Rogério dos Reis Caldas ${ }^{1}$; \\ Leonardo Mateus Teixeira de Rezende ${ }^{1}$; Kaitlin Hughes ${ }^{3}$; \\ Eduardo Oliveira de Souza 3; Miguel Araújo Carneiro-Júnior 1 \\ 1. Physical Education Department. Federal University of Viçosa, Brazil. \\ 2. Institute of Biological Science and Health. Campus Florestal, Federal University of Viçosa, Brazil. \\ 3. Human Performance Laboratory. Health Sciences and Human Performance Department. \\ University of Tampa, United States of America.
}

\begin{abstract}
Introduction: The resistance exercise (RE) is recommended for whole population. However, some variables can promote different physiological responses during the performance, with a direct impact on cardiovascular responses. Thus, the objective was to verify the cardiovascular responses to three RE protocols between beginners (BG) and advanced (AD) practitioners. Methods: thirty male resistance training practitioners divided into two groups: BG and AD. The volunteers were studied during three protocols of bench press exercise: $1: 15$ repetitions at $65 \%$ of one maximal repetition (1RM); $2: 8$ repetitions at $80 \%$ of $1 \mathrm{RM} ; 3: 4$ repetitions at $90 \%$ of $1 \mathrm{RM}$. The systolic blood pressure (SBP), diastolic blood pressure (DBP), heart rate (HR) and rate pressure product (RPP) were measured before and after the protocols. Results: there was a significant increase in HR, SBP, DBP and RPP from rest to post exercise. The AD participants showed lower values of HR, SBP and RPP in the protocol 1 compared to 2 and 3; and presented higher values of HR and RPP in protocol 3 compared to 2. Discussion: the three protocols increased the cardiovascular overload compared to rest values, and no differences were observed between groups. In AD, the intensity seems to produce more cardiovascular overload than the volume or the total training load. Keywords: resistance training, cardiovascular effort, heart rate, blood pressure
\end{abstract}

\section{RESPUESTAS CARDIOVASCULARES DE PROFESIONALES PRINCIPIANTES Y AVANZADOS A DIFERENTES PROTOCOLOS DE EJERCICIO DE RESISTENCIA DE VOLUMEN E INTENSIDAD}

\section{RESUMEN}

Introducción: el ejercicio de resistencia (RE) se recomienda para toda la población. Sin embargo, algunas variables pueden promover diferentes respuestas fisiológicas durante el desempeño, con un impacto directo en las respuestas cardiovasculares. Por lo tanto, el objetivo era verificar las respuestas cardiovasculares a tres protocolos RE entre los principiantes (BG) y los practicantes avanzados (AD). Métodos: treinta practicantes de entrenamiento de resistencia masculinos divididos en dos grupos: BG y AD. Los voluntarios fueron estudiados durante tres protocolos de ejercicio de press de banca: 1:15 repeticiones al 65\% de una repetición máxima (1RM); $2: 8$ repeticiones al 80\% de 1RM; 3: 4 repeticiones al 90\% de 1RM. La presión arterial sistólica (PAS), la presión arterial diastólica (PAD), la frecuencia cardíaca (FC) y el producto de presión arterial (RPP) se midieron antes y después de los protocolos. Resultados: hubo un aumento significativo en HR, SBP, DBP y RPP desde el reposo hasta el ejercicio. Los participantes de AD mostraron valores más bajos de HR, SBP y RPP en el protocolo 1 en comparación con 2 y 3; y presentaron valores más altos de HR y RPP en el protocolo 3 en comparación con 2. Discusión: los tres protocolos aumentaron la sobrecarga cardiovascular en comparación con los valores de reposo, y no se observaron diferencias entre los grupos. En AD, la intensidad parece producir más sobrecarga cardiovascular que el volumen o la carga de entrenamiento total. 
Palabras clave: entrenamiento de resistencia, esfuerzo cardiovascular, frecuencia cardíaca, presión arterial

Correspondence:

Miguel Araújo Carneiro-Júnior

Physical Education Department. Federal University of Viçosa, Brazil.

miguel.junior@ufv.br

Submitted: 07/04/2020

Accepted: 22/06/2020 


\section{INTRODUCTION}

The resistance exercise (RE) is recommended for whole population, since this promote health benefits, such as physical fitness, strength gains, flexibility, reduced body fat, blood pressure (BP) control and blood glucose metabolism (Dutra, Lima, Mota, Oliveira, \& Veloso, 2013; Jakicic et al., 2001; Kohrt, Bloomfield, Little, Nelson, \& Yingling, 2004). However, some training variables, like intensity and volume, can promote different physiological responses during the performance of RE, with a direct impact on cardiovascular safety during training (Correa Neto et al., 2017; 0.C; Moreira et al., 2017). In healthy men, the blood pressure can reach values of 320 and $250 \mathrm{mmHg}$ for systolic (SBP) and diastolic blood pressure (DBP), respectively, during concentric phase of RE performed until fatigue (MacDougall, Tuxen, Sale, Moroz, \& Sutton, 1985).

Previous studies suggest that intensity exerts a more pronounced effect on cardiovascular responses, than volume (Figueiredo, Willardson, et al., 2015; O.C; Moreira, et al., 2017). However, even at low loads, maintenance of muscle contractions for long periods can also induce high cardiovascular stress (Figueiredo, Rhea, et al., 2015). Thus, it is possible to consider that both higher intensities and volumes can result in higher cardiovascular demand. However, at present, it is not clear which of these variables cause a more elevated cardiovascular stress.

It is known that the RE promotes significant increases in heart rate (HR) and BP (Darr, Bassett, Morgan, \& Thomas, 1988). In addition, trained individuals showed parasympathetic reactivation enhanced, that's affect the HR return to baseline levels, occurring more quickly than untrained (Darr, et al., 1988). This suggests that chronic adaptations to RE lead to different acute cardiovascular responses between advanced (AD) and beginners (BG) during and immediately after RE.

Thus, we hypothesized that the cardiovascular responses will be higher in beginners than advanced practitioners. In addition, a RE performed prioritizing intensity would produce more pronounced cardiovascular responses in HR, BP and rate pressure product (RPP) than protocol prioritizing volume. Therefore, this study aimed to verify and compare the cardiovascular responses to three RE protocols performed with different volumes and intensities between beginners and advanced practitioners.

\section{METHOD}

\section{Experimental approach to the problem}

This was a parallel group repeated measures design, which investigated the cardiovascular responses to three RE protocols performed with high volume and low intensity (Protocol 1: 15 repetitions at 65\%- 15/65\%), moderate volume and moderate intensity (Protocol 2: 8 repetitions at 80\%-8/80\%), and 
low volume and high intensity (Protocol 3: 4 repetitions at 90\%- 4/90\%) between beginners and advanced practitioners. Both groups were submitted to the same procedures. Participants performed a one repetition maximum test (1RM) in bench press exercise and 48 hours after, they performed one of three different protocols in a randomized order separated by 48 hours for each protocol. HR, SBP and DPB were evaluated before and immediately after the protocol using standard measurements by the same researcher.

\section{Participants}

The sample consisted of 30 healthy males between 18 and 30 years of age who had at least one year or less than six months of experience with RE. The exclusion criteria adopted was: a) skeletal muscle limitations; b) positive PAR$\mathrm{Q}$; c) cardiovascular diseases; d) use of drugs that could influence the cardiovascular responses.

The participants answered a questionnaire of readiness to practice physical activity (PAR-Q), and completed the coronary risk table. They also answered a complete anamnesis, which provided information about their health, and signed the consent form.

After these initial procedures, the participants were divided into two groups based on their experience with RE. One group consisted of 15 beginners in RE (BG: less than six months of RE), another with 15 advanced in RE (AD: at least one year of experience in RE) ("American College of Sports Medicine position stand. Progression models in resistance training for healthy adults," 2009).

All study procedures were in accordance with the Guidelines and Norms Regulating Research Involving Human Beings (Resolution 196/96 of the National Health Council-Brazil), being previously approved by the ethics committee in research with humans of the Federal University of Viçosa $(072 / 2010)$, and each participant signed a free and informed consent form.

\section{Anthropometric assessments}

The body weight was measured by a mechanical scale (model Star 300/4; Filizola, São Paulo, Brazil). The height was measured using a wall stadiometer (model Professional ES2020; Sanny, São Paulo, Brazil). Height and weight were used to calculate the body mass index (BMI). All measurements were performed following the recommendations of the International Standards for Anthropometric Assessment (Stewart, Marfell-Jones, \& Olds, 2011.).

\section{Muscular strength assessments}

All data was collected at the Laboratory of Strength of the Federal University of Viçosa by an experienced examiner. The mass of each plate and 
bar used in this study was determined using the mechanical scale (model Star 300/4; Filizola, São Paulo, Brazil).

The one-repetition maximum (1RM) test was performed on a bench press apparatus (FS3060 model, Righetto, Brazil). The 1RM test was preceded by a warm-up set (10-12 repetitions) with a load between $40-60 \%$ be used at the first attempt of the $1 \mathrm{RM}$ test. The testing started two minutes after the warm up. To standardize the $1 \mathrm{RM}$ test, all participants started the test in the supine position and with shoulders flexed $90^{\circ}$ in relation to the trunk, the arms remained extended and the footprint on the bar was made in pronation. Starting from the initial position, the participants performed a horizontal abduction of the shoulder reaching a $90^{\circ}$ flexion of the elbows, bringing the bar close to the sternum. Then, elbow extension was performed with horizontal shoulder adduction, taking the bar to the initial position.

Each subject started the 1RM trials with a weight that they believed could lift using maximum effort. Weight increments were then added until they reached the maximum load that could be lifted once. If the participant could not perform a single repetition, approximately $2-5 \%$ was subtracted from the load employed in the test (O.C; Moreira et al., 2017). The participants rested for 3-5 min between the attempts. All participants made a maximum of three attempts to determine $1 \mathrm{RM}$. The participants performed the tests at the same time of the day and did not practice any physical exercise before. To reduce possible errors in the 1RM measures, standardized instructions how to execute the exercise were provided to participants prior to the start of the test; the movements were monitored and, if necessary, adjusted during the tests; all participants were verbally encouraged during the test (O.C; Moreira, et al., 2017).

The total load of each protocol was calculated by multiplying the weight lifted by the number of repetitions of each protocol. The value of total load was expressed in kilograms $(\mathrm{Kg})$.

\section{Cardiovascular assessments}

The HR, SBP, DPB and RPP were determined before (at resting condition) and immediately after each protocol of bench press exercise.

For resting evaluation, the participants were maintained for 10 minutes in a calm and quiet environment, followed by measures of resting BP and HR in the supine position. Resting HR was determined using a heart monitor (model FT7, Polar, Finland). The measurement was recorded for 10 minutes, which computed the mean value of the last 2-minutes.

The resting SBP and DBP were measured using calibrated sphygmomanometer with a standard cuff for adults and a stethoscope (Premium Brand Model, Single, China). The measurements and the classification of the results were carried out according to the international 
guidelines(Chobanian et al., 2003) and followed by the Brazilian Society of Cardiology. The RPP was calculated by multiplying SBP and HR (McArdle, Katch, \& Katch, 2011).

Immediately after each protocol the cardiovascular responses were measured. The HR was the highest value presented at the end of the protocol, and SBP and DBP were measured with the cuff being inflated during the last repetition and performed within a maximum of 10 seconds after the last repetition (O.C; Moreira, et al., 2017; O.C; Moreira, et al., 2017; M.D; Polito \& Farinatti, 2003).

\section{Experimental sessions}

To avoid a treatment order effect interference, we used a balanced crossover design, based on Latin Squares, in which the groups performed the protocols at different sequences (Jesus, Moreira, Oliveira, Doimo, \& Monteiro, 2013; Moreira, Castro, Carneiro-Júnior, Teodoro, \& Oliveira, 2013; O.C; Moreira, et al., 2017).

A 48-hour interval was taken between the protocol executions. To prevent variation in the speed of movement, the exercises were performed using a metronome set to 60 beats per minute, with the concentric and eccentric phases lasting 2 seconds each.

The participants were instructed not to hold their breath during the exercises. During the exercise protocols, the researcher was positioned beside the volunteer to measure HR and BP.

\section{Statistical analysis}

The data were presented using mean and standard error. Shapiro Wilk test was performed to verify the normality of the data. The data showed different distribution, being that RPP and DBP showed non-parametric, and HR, SBP, $1 \mathrm{RM}, \mathrm{BM}$ and load analysis showed parametric distribution. Therefore, the Student $\mathrm{T}$ test was used when parametric, and Mann-Whitney test applied when non-parametric distribution, aiming to compare the variables between groups. The Wilcoxon test was used for non-parametric and Paired test for parametric distribution, aiming to compare pre and post-exercise variables. Friedman's test was used to non-parametric, while ANOVA one way was used to parametric data, and the Wilcoxon post hoc was applied to verify HR, SBP, DBP and RPP behavior among the three different values of volume and intensity. The effect size was calculated by Cohen's $d$ for intragroup and intergroup comparisons, with confidence interval of $95 \%$. The effect size was classified as trivial $(<0.5)$, small $(0.5-1.25)$, moderate $(1.25-1.9)$ and large $(>2.0)$ (Rhea, 2004). For all treatments, a significance level of $\mathrm{p}<0.05$ was adopted and the Statistical Package for the Social Sciences (SPSS) v.23.0 was used. 


\section{RESULTS}

All protocols were performed with the same volume and relative load in the two groups. However, the AD lifted a greater absolute load than the $\mathrm{BG}$ (Protocol 1: $\mathrm{BG}=28.51 \mathrm{Kg}$ vs. $\mathrm{AD}=67.52 \mathrm{Kg}$; Protocol 2: $\mathrm{BG}=35.09 \mathrm{Kg}$ vs. $\mathrm{AD}=$ 82.61 Kg; Protocol 3: $B G=39.48 \mathrm{Kg}$ vs. $A D=92.88 \mathrm{Kg} ; \mathrm{p}<0.001)$.

The description of the anthropometric characteristics and the variables at rest are presented in Table 1 . The sample did not present statistically significant differences for the following variables: age, weight, height, BMI, HR, SBP and RPP at rest. The AD showed higher values of $1 \mathrm{RM}(\mathrm{p}<0.001)$ and DBP $(p=0.016)$ than the BG.

TABLE 1

Description and comparison of anthropometrics and cardiovascular variables at rest.

\begin{tabular}{lllllll}
\hline \hline & \multicolumn{2}{c}{ BG } & \multicolumn{2}{c}{ AD } \\
\hline Variable & Mean & SD & Mean & SD & P value & d (CI95\%) \\
\hline Age (years) & 22.1 & 2.1 & 21.6 & 2.2 & 0.567 & $-0.21(-0.93 ; 0.50)$ \\
Weight (Kg) & 74.0 & 13.2 & 80.9 & 6.5 & 0.056 & $0.53(-0,20 ; 1,25)$ \\
Height (cm) & 180 & 10 & 1.80 & 0.10 & 0.081 & $0.50(-0.22 ; 1.22)$ \\
BMI (Kg/m $\left.{ }^{2}\right)$ & 24.3 & 3.4 & 24.9 & 1.7 & 0.806 & $0.21(-0.50 ; 0.93)$ \\
1RM (Kg) & 43.9 & 9.5 & 103.2 & 18.3 & $<0.001$ & $6.27(4.91 ; 7.63)$ \\
HR (bpm) & 69.3 & 7.9 & 67.7 & 7.9 & 0.512 & $-0.20(-0.92 ; 0.51)$ \\
SBP (mmHg) & 114.0 & 10.6 & 120.7 & 5.9 & 0.067 & $0.63(-0.09 ; 1.36)$ \\
DBP (mmHg) & 72.7 & 7.9 & 80.0 & 3.8 & 0.016 & $0.92(0.18 ; 1.65)$ \\
RPP (mmHg.bpm) & 7890.7 & 1089.9 & 8080.7 & 757.7 & 0.744 & $0.17(-0.54 ; 0.89)$ \\
\hline \hline
\end{tabular}

BG: beginners group ( $n=15) ; A D$ : advanced group ( $n=15) ; S D$ : standard error; BM: body mass; 1RM: maximal repetition; HR: heart rate; SBP: systolic blood pressure; DBP: diastolic blood pressure; RPP: rate pressure product; d: Cohen's d effect size; CI95\%: confidence interval of $95 \%$.

Table 2 presents the comparison of the cardiovascular responses measured before the RE session and immediately after for both groups. The three protocols promoted a significant increase in all cardiovascular variables of both groups. The only exception was the DBP of AD in the protocol 1, that didn't show significant differences between pre and post moments $(p=0.364)$. In AD group, greater HR was observed in protocol 3 compared to 2 and $1(p<0.001)$; and higher RPP of protocol 3 in relation to $1(\mathrm{p}<0.05)$. 
TABLE 2

Description and comparison of cardiovascular variables between pre and post exercise moments.

\begin{tabular}{|c|c|c|c|c|c|c|}
\hline & \multicolumn{3}{|c|}{ BG } & \multicolumn{3}{|c|}{ AD } \\
\hline Variable & $\begin{array}{c}\text { Pre-exercise } \\
\text { Mean (SD) }\end{array}$ & $\begin{array}{c}\text { Post-exercise } \\
\text { Mean (SD) }\end{array}$ & d(CI95\%) & $\begin{array}{c}\text { Pre-exercise } \\
\text { Mean (SD) }\end{array}$ & $\begin{array}{c}\text { Post-exercise } \\
\text { Mean (SD) }\end{array}$ & d(CI95\%) \\
\hline \multicolumn{4}{|c|}{ Protocol $1(15 / 65 \%)$} & \multicolumn{3}{|c|}{ Protocol $1(15 / 65 \%)$} \\
\hline HR (bpm) & $68.2(8.2)$ & $114.1(13.7)^{* *}$ & $5.58(4.33 ; 6.84)$ & $66.7(7.3)$ & $111.8(10.7)^{* *} \Psi$ & $6.12(4.78 ; 7.46)$ \\
\hline $\mathrm{SBP}(\mathrm{mmHg})$ & $116.6(7.2)$ & $140.0(9.2)^{* *}$ & $3.22(2.29 ; 4.16)$ & $118.6(5.1)$ & $138.6(8.3)^{* *}$ & $3.87(2.86 ; 4.89)$ \\
\hline DBP (mmHg) & $72.0(8.6)$ & $82.6(7.4)^{*}$ & $1.24(0.49 ; 1.99)$ & $78.6(5.1)$ & $81.3(9.1)$ & $0.52(-0.21 ; 1.24)$ \\
\hline RPP (mmHg.bpm) & $7949.3(936.8)$ & $15980.0(2120.6)^{* *}$ & $8.57(6.83 ; 10.31)$ & $7914.6(874.1)$ & $15544.6(1999.8)^{* *} \dagger$ & $8.73(6.96 ; 10.49)$ \\
\hline \multicolumn{4}{|c|}{ Protocol $2(8 / 80 \%)$} & \multicolumn{3}{|c|}{ Protocol $2(8 / 80 \%)$} \\
\hline HR (bpm) & $69.1(7.8)$ & $111.1(11.8)^{* *}$ & $5.38(4.16 ; 6.61)$ & $67.8(8.1)$ & $118.7(8.7)^{* *} \Psi$ & $6.24(4.88 ; 7.60)$ \\
\hline SBP (mmHg) & $117.3(9.6)$ & $142.6(17.1)^{* *}$ & $2.64(1.77 ; 3.50)$ & $119.3(7.0)$ & $144.0(9.1)^{* *}$ & $3.51(2.54 ; 4.47)$ \\
\hline DBP (mmHg) & $71.3(7.4)$ & $83.3(9.0)^{* *}$ & $1.61(0.84 ; 2.39)$ & $77.3(4.5)$ & $82.6(7.4)^{*}$ & $1.17(0.42 ; 1.91)$ \\
\hline RPP (mmHg.bpm) & $8096.6(970.6)$ & $15944.0(2899.6)^{* *}$ & $8.08(6.43 ; 9.74)$ & $8085.3(929.9)$ & $17123.3(1895.4)^{* *}$ & $9.72(7.79 ; 11.65)$ \\
\hline \multicolumn{4}{|c|}{ Protocol $3(4 / 90 \%)$} & \multicolumn{3}{|c|}{ Protocol $3(4 / 90 \%)$} \\
\hline HR (bpm) & $67.9(8.5)$ & $112.7(15.6)^{* *}$ & $5.25(4.05 ; 6.46)$ & $66.9(7.9)$ & $123.5(9.4)^{* *}$ & $7.10(5.60 ; 8.59)$ \\
\hline SBP (mm Hg) & $116.6(9.0)$ & $140.6(12.0)^{* *}$ & $2.67(1.80 ; 3.54)$ & $119.3(5.9)$ & $148.0(10.8)^{* *}$ & $4.83(3.69 ; 5.97)$ \\
\hline $\mathrm{DBP}(\mathrm{mmHg})$ & 72.6 (7.9) & $83.0(9.9)^{* *}$ & $1.29(0.54 ; 2.05)$ & $78.6(3.5)$ & $85.3(6.4)^{* *}$ & $1.89(1.10 ; 2.69)$ \\
\hline RPP (mmHg.bpm) & $7934.6(1189.9)$ & $15954.6(3094.3)^{* *}$ & $6.74(5.30 ; 8.18)$ & $7974.6(885.8)$ & $18314.0(2145.6)^{* *}$ & $11.67(9.40 ; 13.94)$ \\
\hline
\end{tabular}

BG: beginners group (n=15); AD: advanced group ( $n=15) ; S D$ : standard error; HR: heart rate; SBP: systolic blood pressure; DBP: diastolic blood pressure; RPP: rate pressure product; $d$ : Cohen's $d$ effect size; CI95\%: confidence interval of 95\%; * p<0.05 pre vs. post; ** p<0.001 pre vs. post; $\dagger$ $p<0.05$ vs. Protocol 3; $\Psi$ p $<0.001$ vs. Protocol 3. 
Table 3 presents the comparison of cardiovascular responses variation (delta) between groups and protocols. Regarding cardiovascular parameters, the only difference observed was in the protocol 3, where AD presented higher RPP than BG $(\mathrm{p}=0.017)$.

AD showed more elevated HR and RPP in protocol 3 than $1(\mathrm{p}<0.001)$ and 2 $(\mathrm{p}=0.012)$, and higher SBP in protocol 3 than $1(\mathrm{p}=0.019)$, although the total load was higher in protocol 1. Furthermore, protocol 2 produced greater HR $(\mathrm{p}=0.012)$ and RPP than protocol $1(\mathrm{p}<0.001)$, although the total load was higher in protocol 1.

TABLE 3

Description and comparison of absolute differences (Delta $[\Delta]$ ) form pre to post exercise moments, between beginners and advanced participants.

\begin{tabular}{cccc}
\hline \hline Variable & BG & AD & d(CI95\%) \\
\hline & Protocol 1 (15/65\%) & \\
\hline HR (bpm) & $45.9(11.7)$ & $45.1(9.9)$ & $-0.06(-0.78 ; 0.65)$ \\
\hline SBP (mmHg) & $23.3(9.8)$ & $20.0(8.5)$ & $-0.34(-1.06 ; 0.38)$ \\
\hline DBP (mmHg) & $10.7(13.3)$ & $2.7(11.0)$ & $-0.60(-1.32 ; 0.12)$ \\
\hline RPP (mmHg.bpm) & $8030.7(1764.6)$ & $7630.0(1724.2)$ & $-0.23(-0.94 ; 0.49)$ \\
\hline Total load (Kg) & $427.7(92.1)$ & $1006.2(177.9)^{*}$ & $6.27(4.91 ; 7.64)$ \\
\hline \multicolumn{4}{c}{ Protocol 2 (8/80\%) } \\
\hline HR (bpm) & $42.0(15.6)$ & $50.9(7.9)^{\ddagger}$ & $0.57(-0.15 ; 1.29)$ \\
\hline SBP (mmHg) & $25.3(11.3)$ & $24.7(9.9)$ & $-0.06(-0.78 ; 0.66)$ \\
\hline DBP (mmHg) & $12.0(13.2)$ & $5.3(8.3)$ & $-0.50(-1.23 ; 0.22)$ \\
\hline RPP (mmHg.bpm) & $7847.3(2982.3)$ & $9038.0(1666.3) \Psi$ & $0.40(-0.32 ; 1.12)$ \\
\hline Total load (Kg) & $280.7(60.5)$ & $660.4(116.7)^{*} \neq$ & $6.27(4.91 ; 7.64)$ \\
\hline \multicolumn{4}{c}{ Protocol 3 (4/90\%) } \\
\hline HR (bpm) & $44.8(19.3)$ & $56.6(11.1)^{\Psi \#}$ & $0.61(-0.11 ; 1.34)$ \\
\hline SBP (mmHg) & $24.0(11.1)$ & $28.7(9.9)^{\ddagger}$ & $0.42(-0.30 ; 1.14)$ \\
\hline DBP (mmHg) & $10.3(13.4)$ & $6.7(7.2)$ & $-0.27(-0.99 ; 0.44)$ \\
\hline RPP (mmHg.bpm) & $8020.0(3144.1)$ & $10339.3(2089.5)^{*} \Psi \#$ & $0.74(0.01 ; 1.47)$ \\
\hline Total load (Kg) & $157.9(34.0)$ & $371.5(65.7)^{*} \ddagger \#$ & $6.27(4.91 ; 7.64)$ \\
\hline \hline
\end{tabular}

$B G$ : beginners group ( $n=15) ; A D$ : advanced group ( $n=15) ; S D$ : standard error; HR: heart rate; SBP: systolic blood pressure; DBP: diastolic blood pressure; RPP: rate pressure product; $d$ : Cohen's d effect size; C195\%: confidence interval of 95\%; * $p<0.05 v s . B G ; \neq$ $p<0.05$ vs. protocol 1; $\Psi$ p<0.001 vs. Protocol 1; \# $p<0.05$ vs. protocol 2.

\section{DISCUSSION}

The aim of this study was to compare the cardiovascular responses to three RE protocols performed with different volumes and intensities between BG and AD participants. The main findings of the study were: 1) the three protocols promoted increases in cardiovascular variables in both groups; 2) no differences were observed in cardiovascular overload between BG and AD; 3) in the BG, no differences were observed in cardiovascular overload between the protocols; 4) the increased responses of cardiovascular parameters were 
promoted by the intensity in the AD. The behavior of all cardiovascular variables evaluated during the three protocols of RE showed significant increases with a large effect size in relation to the rest condition, similar to that observed in other studies (Agarwal et al., 2017; Jesus, et al., 2013; Moreira, et al., 2013; O.C; Moreira, et al., 2017; O.C; Moreira, et al., 2017; Taylor, Wiles, Coleman, Sharma, \& O'Driscoll J, 2017). A possible explanation to this increase could be the compression of blood vessels by the muscles involved in the exercise (MacDougall, et al., 1985). Activation of both chemoreceptors and muscle and joint mechanoreceptors promote the increased sympathetic and decreased parasympathetic cardiovascular modulation (Ichinose, Watanabe, Fujii, Kondo, \& Nishiyasu, 2013). This physiological response to RE probably occur due to impulses from the motor cortex to the cardiovascular control center and to increase in peripheral vascular resistance caused by partial occlusion of blood flow (O.C; Moreira, et al., 2017).

We hypothesized that the cardiovascular responses will be larger in BG than in AD. Based on our results, the training experience seems to not have an effect on cardiovascular responses, once no differences were observed in the analyzed variables between groups. Further, the comparison of all variables between groups showed only a trivial or small effect size. Banister et al. (1999) provided a theory about human performance, suggesting that the exercise practice can promote an input in the form of training impulses and an output in the form of performance (Banister, Carter, \& Zarkadas, 1999). Thus, the human performance should be a result of the difference between the fitness gain and the fatigue. In accordance with this theory, a person with high training experience can present a better physiological response to an exercise session. At the cardiovascular point of view, the training experience is associated with an enhanced stroke volume, cardiac output, and morphofunctional adaptations of the myocardium (Lavie et al., 2015; McNarry \& Jones, 2014). These cardiovascular adaptations to exercise demonstrate that the most trained participants could show less pronounced cardiovascular responses. However, we didn't find studies comparing the cardiovascular behavior during RE in people with different training levels. We hypothesized that a RE performed with protocol prioritizing greater intensity would produce more pronounced cardiovascular responses in HR, BP and RPP than protocol prioritizing volume. Based on our results, only the AD presented this accentuated cardiovascular response due to greater intensity in relation to volume. The different RE protocols produced similar cardiovascular responses in the BG. Generally, the studies that evaluated the effect of different loads on cardiovascular responses used men with previous experience in RE (Castinheiras-Neto, Costa-Filho, \& Farinatti, 2010; Correa Neto, et al., 2017; Figueiredo, Willardson, et al., 2015). Correa Neto et al. (2017) found that cardiovascular responses were 
accentuated after the practice of RE with $80 \%$ of load in relation to the series with $60 \%$ (Correa Neto, et al., 2017), similar to our results. A second study compared the acute hemodynamic and cardiovascular responses of high load/low repetition RE to low load/high repetition RE (Gjovaag, Hjelmeland, Oygard, Vikne, \& Mirtaheri, 2016). Cardiovascular overload seemed to be related to training duration and not to the intensity (Gjovaag, et al., 2016). This set of information shows that is necessary to carry out new studies, with more than one set per protocol, in order to better understand the cardiovascular responses of $\mathrm{BG}$.

The volunteers of AD group showed higher cardiovascular responses in the protocol with higher intensity and low volume. These results are in accordance with some studies (Correa Neto, et al., 2017; Figueiredo, Willardson, et al., 2015; O.C; Moreira, et al., 2017) made with trained people, showing that the intensity of exercise promote a more pronounced cardiovascular response to RE, either during or after the exercise. It may be explained by the exercise intensity which is related to increased sympathetic nerve activity. After the execution of RE, metabolites are released into the bloodstream triggering muscle chemoreceptors, which leads the sympathetic nervous system to release catecholamines, resulting in increased cardiovascular responses (O.C; Moreira, et al., 2017; Rowell \& O'Leary, 1990). This mechanism could be responsible for the adequacy of the distribution of blood flow and circulatory perfusion to the active muscles (Lopes, Gonçalves, \& Resende, 2006).

There are others ways to modulate cardiovascular responses in RE training, including the velocity of contraction and RE series until failure (De Souza et al., 2013; Lamotte, Fleury, Pirard, Jamon, \& van de Borne, 2010). The velocity of contraction is an important component of RE exercise series. We adopted the rhythm of execution of 2 seconds for both concentric and eccentric phases, that is already related in literature (Braith \& Beck, 2008; Lamotte, et al., 2010). Lamotte et al. (2010) showed that RE using slow execution velocity promote greater cardiovascular adjustments compared to quickly velocity (Lamotte, et al., 2010). The velocity of execution is not the study object in this work, thus, we selected a moderate execution velocity for both phases of movement. In previous study, the failure application during RE series promoted alterations in cardiovascular responses until $24 \mathrm{~h}$ after practice compared to control series (De Souza, et al., 2013). The authors shown that RE until failure promoted a drop in HR in next morning after training, that's important observation, particularly for people with cardiovascular disease. Other interesting result found was the BP reduction immediately after exercise leading to failure. During exercise session, the authors observed higher cardiovascular responses during sets leading to failure, which can be associated to a higher intensity of effort (De Souza, et al., 2013). In our study, it was observed higher HR e RPP 
after session with higher intensity (4/90\%). We didn't follow cardiovascular behavior for a long time after the sessions. However, observing the results of De Souza et al. (2013), it can be postulated that serie with higher intensity promote hypotension process.

This study contributes to the field of knowledge related to the RE prescription, indicating that young healthy adults can safely perform RE at different intensities, regardless of their level of training and experience with RE.

The data further strengthened the importance of controlling the intensity of $\mathrm{RE}$, considering that it was the parameter of greatest influence on the cardiovascular responses. The data also reaffirms the importance of $\mathrm{HR}, \mathrm{BP}$ and RPP to control the cardiovascular stress during RE.

The present study presents some limitations, such as a single serie of RE for each of the protocols applied, once multiple series could increase the ecological validity of the results. However, the use of single sets was a strategy to guarantee safety during testing. Another possible limitation was the utilization of the auscultatory method to assess the BP during RE, that can underestimate the blood pressure, and is important to note that the peak of SBP is observed during the concentric phase of contraction (M.D. Polito, Farinatti, Lira, \& Nobrega, 2007), although this method has validity and reproducibility to indicate differences in BP responses to RE (Castinheiras-Neto, et al., 2010).

The impact of volume and intensity relationship on cardiovascular stress will vary across participants; therefore, it is essential to know the cardiovascular responses to different training variables to prescribe specific programs to each individual. The information provided in this study can assist in prescribing RE, especially for participants with cardiovascular risk factors. Therefore, when prescribing RE for beginner participants, our data suggests that a single set of RE can be used, independently of volume and intensity. For advanced participants, the intensity of the training protocol seems to be a key variable to the cardiovascular safety. However, these results must be analyzed with caution, and future investigations in this field are necessaries, to evaluate the possible effects of different variables, as the set number, time of rest, training methods, etc.

In conclusion, the three protocols promoted the increase of cardiovascular overload compared to rest values. The training experience seems to not affect the cardiovascular response to $\mathrm{RE}$, and in advanced participants, the intensity seems to produce more cardiovascular overload than the volume or the total training load. 


\section{References}

Agarwal, M., Singh, S., Narayan, J., Pandey, S., Tiwari, S., \& Sharma, P. (2017). Cardiovascular Response and Serum Interleukin-6 Level in Concentric Vs. Eccentric Exercise. Journal of clinical and diagnostic research : JCDR, 11(4), CC04-CC08.

American College of Sports Medicine position stand. Progression models in resistance training for healthy adults. (2009). [Practice Guideline

Review]. Medicine and science in sports and exercise, 41(3), 687-708.

Banister, E. W., Carter, J. B., \& Zarkadas, P. C. (1999). Training theory and taper: validation in triathlon athletes. [Clinical Trial]. European journal of applied physiology and occupational physiology, 79(2), 182-191.

Braith, R. W., \& Beck, D. T. (2008). Resistance exercise: training adaptations and developing a safe exercise prescription. Heart Fail Rev, 13(1), 69-79.

Castinheiras-Neto, A. G., Costa-Filho, I. R., \& Farinatti, P. T. (2010). [Cardiovascular responses to resistance exercise are affected by workload and intervals between sets]. [Research Support, Non-U.S. Gov't]. Arquivos Brasileiros de Cardiologia, 95(4), 493-501.

Chobanian, A. V., Bakris, G. L., Black, H. R., Cushman, W. C., Green, L. A., Izzo, J. L., Jr., et al. (2003). Seventh report of the Joint National Committee on Prevention, Detection, Evaluation, and Treatment of High Blood Pressure. Hypertension, 42(6), 1206-1252.

Correa Neto, V. G., Figueiredo, T., Simões, A. D., Bezerra, M. G., Barguti, S. T. P., Bentes, C. M., et al. (2017). Influence of load intensity on blood pressure after a resistance training session. Apunts Medicina de l'Esport, 52(193), 2328.

Darr, K. C., Bassett, D. R., Morgan, B. J., \& Thomas, D. P. (1988). Effects of age and training status on heart rate recovery after peak exercise. The American journal of physiology, 254(2 Pt 2), H340-343.

De Souza, J. C., Tibana, R. A., Cavaglieri, C. R., Vieira, D. C., De Sousa, N. M., Mendes, F. A., et al. (2013). Resistance exercise leading to failure versus not to failure: effects on cardiovascular control. BMC Cardiovasc Disord, 13, 105.

Dutra, M. T., Lima, R. M., Mota, M. R., Oliveira, P. F. A., \& Veloso, J. H. C. L. (2013). Hipotensão pós-exercício resistido: uma revisão de literatura. Revista de Educação Física da UEM, 24(1), 145-157.

Figueiredo, T., Rhea, M. R., Peterson, M., Miranda, H., Bentes, C. M., dos Reis, V. M., et al. (2015). Influence of number of sets on blood pressure and heart rate variability after a strength training session. [Comparative Study

Randomized Controlled Trial]. Journal of strength and conditioning research, 29(6), 1556-1563.

Figueiredo, T., Willardson, J. M., Miranda, H., Bentes, C. M., Reis, V. M., \& Simao, R. (2015). Influence of Load Intensity on Postexercise Hypotension and Heart 
Rate Variability after a Strength Training Session. Journal of strength and conditioning research, 29(10), 2941-2948.

Gjovaag, T., Hjelmeland, A. K., Oygard, J. B., Vikne, H., \& Mirtaheri, P. (2016). Acute hemodynamic and cardiovascular responses following resistance exercise to voluntary exhaustion. Effects of different loadings and exercise durations. J Sports Med Phys Fitness, 56(5), 616-623.

Ichinose, M., Watanabe, K., Fujii, N., Kondo, N., \& Nishiyasu, T. (2013). Muscle metaboreflex activation speeds the recovery of arterial blood pressure following acute hypotension in humans. [Research Support, Non-U.S. Gov't]. American journal of physiology. Heart and circulatory physiology, 304(11), H1568-1575.

Jakicic, J. M., Clark, K., Coleman, E., Donnelly, J. E., Foreyt, J., Melanson, E., et al. (2001). American College of Sports Medicine position stand. Appropriate intervention strategies for weight loss and prevention of weight regain for adults. Med Sci Sports Exerc, 33(12), 2145-2156.

Jesus, R. C. A., Moreira, O. C., Oliveira, C. E. P., Doimo, L. A., \& Monteiro, W. D. (2013). Cardiovascular response in three different resistance exercises to the deltoid muscle. Bioscience Journal, 29(6), 2077-2084.

Kohrt, W. M., Bloomfield, S. A., Little, K. D., Nelson, M. E., \& Yingling, V. R. (2004). American College of Sports Medicine Position Stand: physical activity and bone health. Med Sci Sports Exerc, 36(11), 1985-1996.

Lamotte, M., Fleury, F., Pirard, M., Jamon, A., \& van de Borne, P. (2010). Acute cardiovascular response to resistance training during cardiac rehabilitation: effect of repetition speed and rest periods. Eur J Cardiovasc Prev Rehabil, 17(3), 329-336.

Lavie, C. J., Arena, R., Swift, D. L., Johannsen, N. M., Sui, X., Lee, D. C., et al. (2015). Exercise and the cardiovascular system: clinical science and cardiovascular outcomes. [Review]. Circulation research, 117(2), 207-219.

Lopes, L. T. P., Gonçalves, A., \& Resende, E. S. (2006). Resposta do Duplo Produto e Pressão Arterial Diastólica em Exercício de Esteira, Bicicleta Estacionária e Circuito na Musculação. . Revista Brasileira de Cineantropometria e Desempenho Humano. , 8(2), 53-58.

MacDougall, J. D., Tuxen, D., Sale, D. G., Moroz, J. R., \& Sutton, J. R. (1985). Arterial blood pressure response to heavy resistance exercise. J Appl Physiol (1985), 58(3), 785-790.

McArdle, W. D., Katch, F. I., \& Katch, V. I. (2011). Fisiologia do exercício: energia, nutrição e desempenho humano. . Rio de Janeiro.

McNarry, M., \& Jones, A. (2014). The influence of training status on the aerobic and anaerobic responses to exercise in children: a review. [Review]. European journal of sport science, 14 Suppl 1, S57-68. 
Moreira, O. C., Castro, V. G., Carneiro-Júnior, M. A., Teodoro, B. G., \& Oliveira, C. E. P. (2013). Comportamento da frequência cardíaca, pressão arterial e duplo produto em três tipos de execução dos exercícios de supino. Revista da Sociedade de Cardiologia do Estado de São Paulo, 23(2A), 13-17.

Moreira, O. C., Faraci, L. L., Matos, D. G., Mazini Filho, M. L., Silva, S. F., Aidar, F. F., et al. (2017). Cardiovascular responses to unilateral, bilateral and alternating limb resistense exercise performed using different body segments. Journal of Strength and Conditioning Research Publish Ahead of Print, 1-13.

Moreira, O. C., Olivera, C. E. P., Matosd, D. G., Silva, S. F., Hicknerf, R. C., \& Aidarh, F. J. (2017). Cardiovascular response to strength training is more affected by intensity than volume in healthy subjects. Revista Andaluza de Medicina del Deporte.

Polito, M. D., Farinatti, P. T., Lira, V. A., \& Nobrega, A. C. (2007). Blood pressure assessment during resistance exercise: comparison between auscultation and Finapres. [Comparative Study

Research Support, Non-U.S. Gov't]. Blood pressure monitoring, 12(2), 81-86.

Polito, M. D., \& Farinatti, P. T. V. (2003). Considerations on the measurement of blood pressure in exercises against resistance. Revista Brasileira de Medicina do Esporte., 9(1), 1-9.

Rhea, M. R. (2004). Determining the magnitude of treatment effects in strength training research through the use of the effect size. J Strength Cond Res, 18(4), 918-920.

Rowell, L. B., \& O'Leary, D. S. (1990). Reflex control of the circulation during exercise: chemoreflexes and mechanoreflexes. J Appl Physiol (1985), 69(2), 407-418.

Stewart, A., Marfell-Jones, M., \& Olds, T. (2011.). International standards for anthropometric assessment. New Zealand: The International Society for the Advancement of Kinanthropometry (ISAK).

Taylor, K. A., Wiles, J. D., Coleman, D. D., Sharma, R., \& O'Driscoll J, M. (2017). Continuous Cardiac Autonomic and Hemodynamic Responses to Isometric Exercise. Medicine and science in sports and exercise, 49(8), 1511-1519. 